\title{
Bridle Procedure Revisited
}

\author{
Rajeev Vohra ${ }^{1 *}$, Babaji Thorat ${ }^{2}$ and Avtar Singh ${ }^{3}$ \\ ${ }^{1}$ Senior Consultant and Foot and Ankle Surgeon, Department of Orthopedics, Amandeep Hospital, India \\ ${ }^{2}$ Senior resident, Department of Orthopedics, Amandeep Hospital, India \\ ${ }^{3}$ Head of the Department of Orthopaedics, Amandeep Hospital, India
}

Submission: July 30, 2020; Published: August 17, 2020

*Corresponding author: Rajeev Vohra, Senior Consultant and Foot and ankle surgeon, Department of Orthopaedics, Amandeep Hospital, Model Town, GT Road, Amritsar 143001, India

\section{Abstract}

Foot drop is a common problem faced in daily orthopaedic practice. It is mostly due to overpowering of dorsiflexors of the foot by the plantar flexors, but sometimes it may be due to global paralysis of the muscles around the foot. Posterior tibial transfer to the dorsum of the foot is routinely performed procedure for the treatment of foot drop and different techniques have been recommended to achieve desired function and balance. In this short article we revisit the role of "Bridle Procedure" in foot drop, its advantages and technique used to perform this procedure.

\section{Mini Review}

Paralysis or weakness of dorsiflexors of the ankle result in steppage gait characterized by plantar flexed position of the ankle (foot drop) during the swing phase of walking and at initial ground contact. This type of gait is quite awkward, energy consuming, physically limiting and increases the risk of falling [1,2]. This condition is mostly due to peroneal nerve injury; however, it can result from other neurological causes and some traumatic and systemic causes. The initial treatment of foot drop includes use of ankle foot orthosis, muscle strengthening and tendoachilles stretching. When there is no improvement for more than one year a tendon transfer is often required to obtain a balanced foot that is plantigrade and functional.

The utility of transfer of the tibialis posterior muscle-tendon unit (PTT) to the dorsum of the foot for treatment of drop foot has been well documented in literature. In 1933, Ober reported the use of transferred PTT to obtain dorsiflexion of the foot [3]. He routed the PTT subcutaneously around the tibia to the dorsum of the foot. Transfer through the subcutaneous tissue is quicker and easier and have a greater lever arm and better strength $[4,5]$. With subcutaneous transfer the tendon is palpable superficially and increased friction can lead of formation of adhesions which may compromise the function [6].

In 1954, Watkins et al. [7] described the transfer of the PTT through interosseous membrane and insertion of the tendon to the bone. The tranmembranous route is sounder because of its direct line of pull and better dorsiflexion capability but is less strong due to short lever arm [8]. It also has a few additional risks like possibility of entrapment due to narrowing of opening in the interosseous membrane or adhesions to the membrane, and risk of injuring the neurovascular structures while making a window in the interosseous membrane $[9,10]$.

The "bridle" procedure, a modification of the transfer of the tibialis posterior to the dorsum of the foot was described by Mc Call et al in 1991 [11]. The description of the procedure given by them included tri-tendon anastomosis of peroneus longus, PTT and tibialis anterior in the distal third leg above the ankle extensor retinaculum. The tibialis posterior was transferred anteriorly through the interosseous membrane and the distal stump of peroneus longus was transferred subcutaneously over the ankle to achieve the tri-tendon anastomosis (Figure 1). In their study of 128 procedures, $80 \%$ surgeries were done for cerebral palsy, due to which calcaneus deformity was the most common complication postoperatively. Acute or chronic stretching of this tri-tendon anastomosis was another complication following this procedure, which resulted into decrease in the active dorsiflexion, recurrence of deformity and hindfoot instability. ${ }^{2,11}$ Rodriguez modified bridle procedure to include the transfer of PTT to middle cuneiform to provide bone to tendon insertion to prevent the elongation of PTT which can occur when PTT is only sutured to peroneus longus and tibialis anterior (Figure 2) [12,13]. In his earlier study [12] on 10 patients, all patients became brace free.

In common peroneal nerve palsy one of the commonest causes of foot drop, both dorsiflexors as well as evertors of the 
foot loose power and the unopposed action of the PTT leads to varus deformity. When only deep peroneal nerve is involved dorsiflexors loose their function but the evertors remain functional and balance the pull of PTT. The bony insertion of the TPP to the dorsum of the foot must be adjusted according to the power of the invertors and evertors of the foot to achieve a balanced foot. A more medial or lateral attachment of the PTT can lead to under or over correction of the coronal position of the foot. With bridle procedure it is possible to avoid varus or valgus deformity which may occur with isolated PTT transfer. ${ }^{13}$ The anterior tibialis tendon rerouting technique described by Vigassio and Marcoccio is another technique to avoid varus deformity after PTT transfer [14]. In this technique the anterior tibial tendon insertion is rerouted to lateral cuneiform through a tunnel drilled from medial cuneiform to lateral cuneiform. The anterior tibial tendon is passed under the extensor retinaculum to distal third leg where it is sutured to transferred PTT using Pulvertaft technique.

\section{Figure $1 \& 2$}

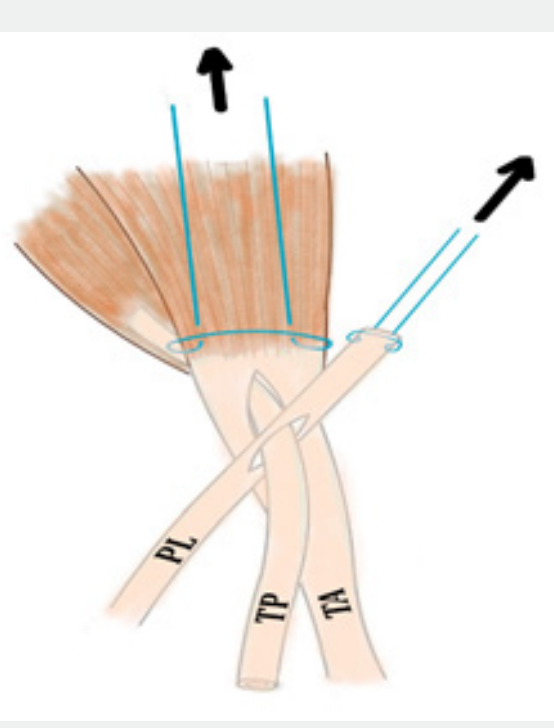

AT: Tibialis Anterior; TP: Tibialis Posterior; PL: Peroneus Longus; PB: Peroneus Brevis

Another technical problem associated with interosseous transfer of PTT is inadequate length of the harvested tendon, which prevents the insertion at the planned site. At times, the length of the harvested tendon is short, and the planned tendon bone insertion is not possible. In such cases transfer of the PPT to dorsiflexors proximal to the extensor retinaculum with bridle procedure is a promising option [2,11-13]. Splitting of the transferred tendon and attaching it to one or more dorsiflexors depending on the muscular imbalance is another recommended procedure $[15,16]$.

In sciatic nerve palsy and post-polio residual paralysis all muscles distal to the knee may get paralysed and patients develop flail foot. Pantalar arthrodesis is a final operation for treatment of such deformities. The rate of complications can be as high as $41 \%$ with pantalar arthrodesis [17]. Pantalar arthrodesis negatively affects the ipsilateral knee on the long run which can be problematic when this procedure is chosen for young individuals [18], Bridle procedure is a useful procedure for this condition as PTT transfer has shown predictable satisfactory long-term results even if the transfer functions solely as a tenodesis [2,1921]. Rodriguez [13] recommended not to use this procedure when the PTT functional grade is two or less, but we have found this procedure useful even in flail foot provided the patients have stable knee and hip.

\section{Operative Technique}

The procedure is performed under a tourniquet. PTT is identified on the plantar aspect of the navicular through a medial incision made over its insertion and detached. Then PTT is exposed proximally in the distal third of the leg by making a longitudinal incision posterior to the medial border of the tibia. The PTT is delivered into this longitudinal incision and tagged with an absorbable suture (Figure 3). When tendoachilles lengthening or gastrocnemius recession is required, it can be done through the same incision.

The third incision is made on the anterior aspect of the distal third leg and anterior tibial muscle is identified, and anterior compartment muscles are retracted to expose the interosseous 


\section{Orthopedics and Rheumatology Open Access Journal (OROAJ)}

membrane. A wide window is made in the interosseous membrane and PTT is transferred around posterior to the tibia and through the interosseus membrane form posterior compartment into the anterior compartment of the lower leg (Figure 4).

\section{Figure 3}
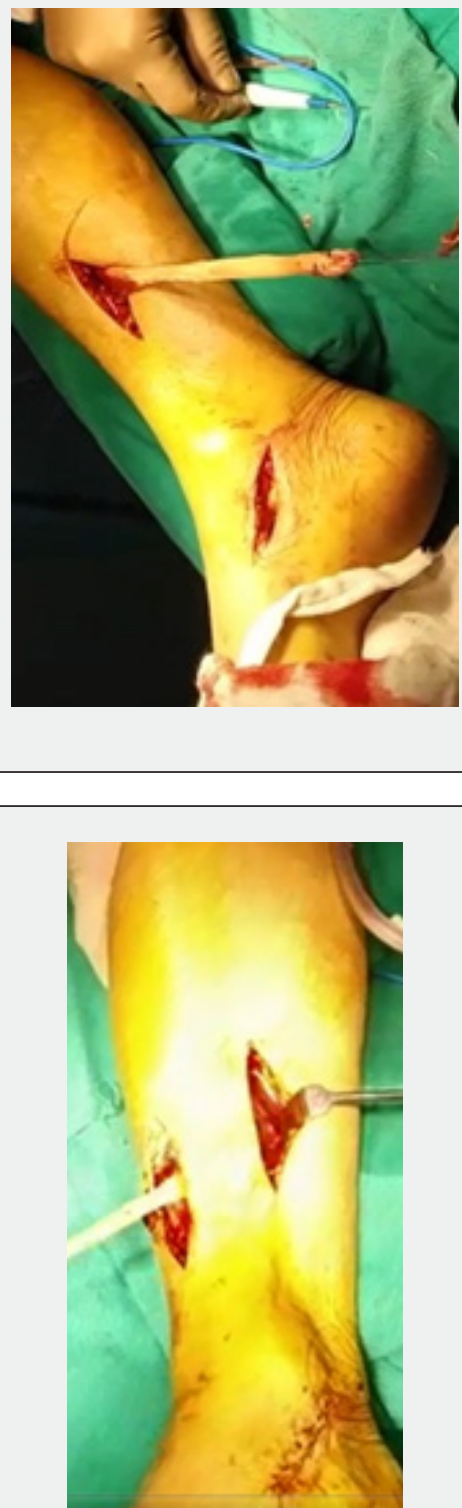

Figure 4

Peroneus longus is located distally by making fourth incision along the peronei on the lateral border of the foot. A fifth incision is made on the lateral aspect of the distal third of the leg and peroneus longus muscle is identified and transected distal to musculotendinous junction (Figure 5). The proximal end of peroneus longus is sutured into the peroneus brevis if the lateral compartment muscles are functional. The transected peroneal tendon is delivered into the already performed incision on the lateral side of the foot. (Figure 6). The peroneus longus tendon is transferred through a subcutaneous tunnel into the already made anterior incision (Figure 7).

The sixth incision is made over the dorsum of the foot over the middle cuneiform, and the insertion point of the tendon on the middle cuneiform is marked with help of the image intensifier. The free distal end of the PTT in anterior compartment is passed through a slit in the tibialis anterior tendon and a slit in the peroneus longus tendon (Figure 8), and then passed under or over the extensor retinaculum of the ankle into the incision 
on the dosum of the foot. The tensioned PTT is inserted in the middle cuneiform with foot in neutral to 5-degree dorsiflexion and secured with an interference screw (Figure 9). The tibialis posterior tendon is then tensioned to about $80 \%$ of its excursion while holding the ankle in neutral and the tendon was fixed in the middle cuneiform.

Figure 5
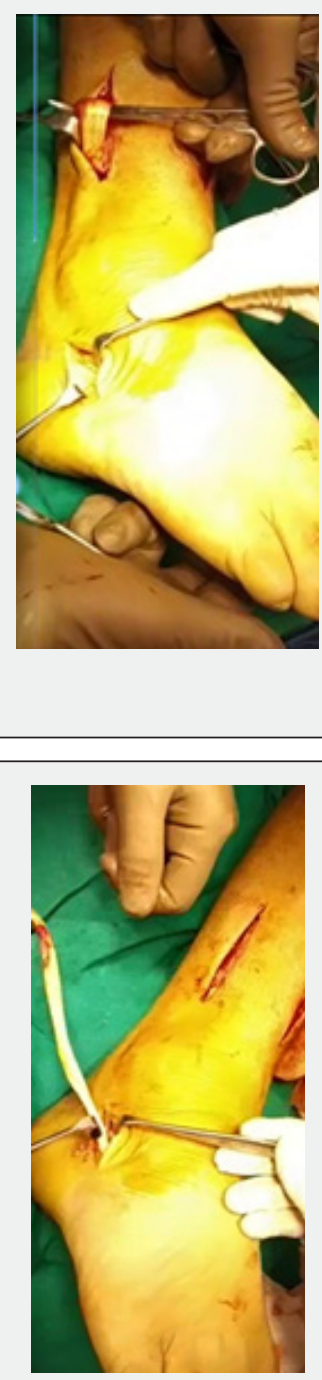

Figure 6

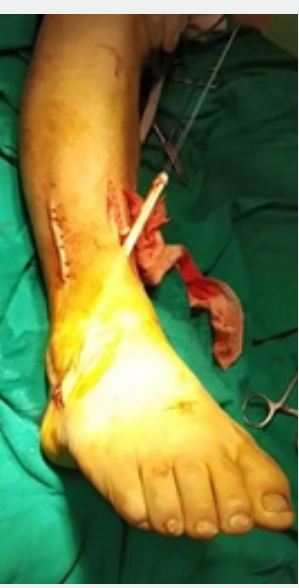

Figure 7 


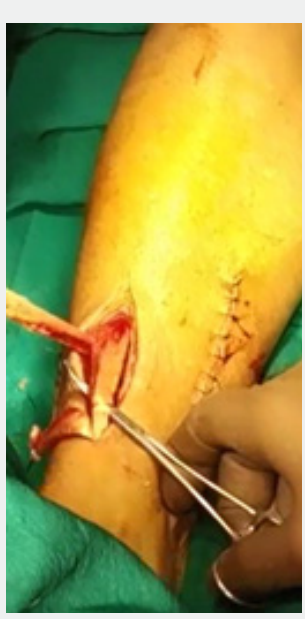

Figure 8

Figure 9

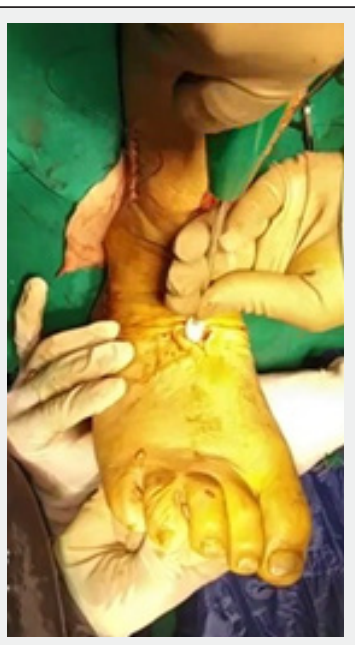

After the insertion of the PTT into middle cuneiform anterior tibial and peroneus longus tendons are sutured to transferred PTT in the incision on the anterior compartment (Figure 10). Post-operatively the foot is immobilized in a splint for two weeks which is changed to cast after removing the sutures at two weeks. two months to strengthen the transferred tendon. Patient is asked to ambulate with ankle foot orthosis or plantar flexion limiting brace for next four months, and most of the patients are brace free in six months. Some patients with flail foot may need to continue the brace to achieve stability during stance phase.

The cast is continued for 8 weeks. Physical therapy is started at

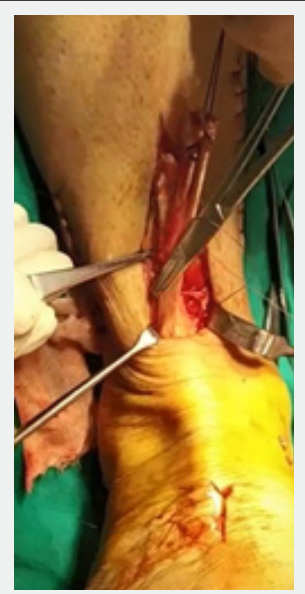


Hastings et al. [22] studied the kinetics and kinematics after the bridle procedure in 18 patients and found that this procedure restores dorsiflexion during the swing phase, however, ankle plantar flexor muscle function was reduced during walking and heel rise. During heel rise there was abnormal midpoint motion, forefoot on hindfoot dorsiflexion instead of plantar flexion. They suggested aggressive rehabilitation to achieve maximum plantarflexion and close monitoring for midfoot dysfunction.

Johnson et al. [23] evaluated 19 patients treated with bridle procedure after two years of surgery with radiographs and Foot and Ankle Ability Measure subscales of activities of daily living and sport, American Orthopaedic Foot \& Ankle Society, and Stanmore scores. They concluded that treatment with bridle procedure leads to significantly improved outcomes and allows discontinuation of use of ankle-foot orthosis. Loss of longitudinal arch due to loss of protective effect of PTT is a concern with this procedure [22,24]. Flynn et al. suggested arthroeresis along with bridle procedure to prevent this complication but could not demonstrate a significant efficacy of this procedure [24].

In summary bridle procedure is effective for foot drop deformity due to various causes. However, the results depend on the remaining power of the muscles around the foot and flexibility of the foot. In flail foot it provides tenodesis effect and markedly improves the gait by keeping the foot neutral during the swing phase. In the presence of flexible flail foot is an attractive alternative to pantalar arthrodesis which is associated with numerous long-term complications. Over tensioning as opposed to under tensioning is preferred in patients with flail foot, when fixing the tendon to middle cuneiform.

\section{References}

1. Myerson MS (2000) Paralytic disorders of the lower extremity. In: Myerson MS, editor. Foot and ankle disorders. Saunders, Philadelphia, USA, pp. 885-891.

2. Prahinski JR, McHale KA, Temple HT, J P Jackson (1996) Bridle transfer for paresis of the anterior and lateral compartment. Foot Ankle Int 17(10): 615-619.

3. Ober FR (1933) Tendon transplantation in the lower extremity. New Eng J Med 209: 52-59.

4. Jeng C, Myerson M (2004) The uses of tendon transfers to correct paralytic deformity of the foot and ankle. Foot Ankle Clin 9(2): 319337

5. Xu J, Geng X, Muhammad H, Xin Ma, Xu Wang, et al. (2014) Posterior tibialis tendon transfer via the circumtibial route: a cadaveric limb analysis. J Orthop Surg Res 9: 121.

6. Wagner E, Wagner P, Zanolli D, Rubén Radkievich, Gunther Redenz, et al. (2018) Biomechanical evaluation of circumtibial and transmembranous routes for posterior tibial tendon transfer for drop foot. Foot Ankle Int 39(7): 843-849.
7. Watkins MB, Jones JB, Ryder CT, Brown Thomas H (1954) Transplantation of the posterior tibial tendon. J Bone Joint Surg Am 36-A(b): 1181-1189.

8. Shane A, Reeves C, Cameron J, Vazales R (2016) Posterior tibial tendon transfer. Clin Podiatr Med Surg 33: 29-40.

9. Hove LM, Nilsen PT (1998) Posterior tibial tendon transfer for drop foot. 20 cases followed for 1-5 years. Acta Orthop Scand 69(6): 608610.

10. Ozkan T, Tuncer S, Ozturk K, Aydin A, Ozkan S (2007) Surgical restoration of drop foot deformity with tibialis posterior tendon transfer. Acta Orthop Traumatol Turc 41(4): 259-265.

11. McCall RE, Frederick HA, McCluskey GM, Riordan DC (1991) The bridle procedure: a new treatment for equinus and equinovarus deformities in children. J Pediatr Orthop 11(1): 83-89.

12. Rodriguez RP (1992) The Bridle procedure in the treatment of paralysis of the foot. Foot Ankle. 13(2): 63-69.

13. Rodriguez RP (2009) The bridle procedure for the treatment of dorsiflexion paralysis of the foot. Tech Foot Ankle Surg 8(4): 168-171.

14. Vigasio A, Marcoccio I (2012) Correction of drop foot in common peroneal nerve palsy: The anterior tibialis tendon rerouting technique. Tech foot Ankle Surg 11(3): 140-149.

15. Hansen Jr ST (2000) Functional reconstruction of the foot and ankle. Lippincott Williams \& Wilkins, Philadelphia, US.

16. Wagenaar FCBM, Louwerens JWK (2007) Posterior tibial transfer: Results of fixation to the dorsiflexors proximal to the ankle joint. Foot Ankle Int 28(11): 1128-1142.

17. Acosta R, Ushiba J, Cracchiolo A $3^{\text {rd }}$ (2000) The results of a primary and staged pantalar arthrodesis and tibiotalocalcaneal arthrodesis in adult patients. Foot Ankle Int 21(3): 182-194.

18. Provelengios S, Papavasiliou KA, Kyrkos MJ, Fares E Sayegh, John M Kirkos, et al. (2009) the role of pantalar arthrodesis in the treatment of paralytic foot deformities. J bone Joint Surg Am 91(3): 575-583.

19. Richardson DR, Gause LN (2011) The bridle procedure. Foot Ankle Clin N Am 16: 419-433.

20. Matusak SA, Baker EA, Fortin PT (2013) The adult paralytic foot. J Am Acad Orthop Surg 21: 276-285.

21. Schweitzer KM, Jones CP (2014) Tedon transfers for the drop foot. Foot Ankle Clin N Am 19(1): 65-71.

22. Hastings MK, Sinacore DR, Woodburn J, E. Scott Paxton, Sandra E Klein, et al. (2013) Kinetics and kinematics after the bridle procedure for treatment of traumatic foot drop. Clin Biomech (Bristol, Avon) 28(5): 555-561.

23. Johnson JE, Paxton ES. Lippe J, Kathryn L Bohnert, David R Sinacore, et al. (2015) outcomes of the bridle procedure for the treatment of foot drop. Foot Ankle Int 36(11): 1287-1296.

24. Flynn J, Wade A, Bustillo J, Juliano P (2015) Bridle procedure combined with a subtalar implant. A case series and review of literature. Foot Ankle Spl 8(1): 29-35. 
Your next submission with Juniper Publishers will reach you the below assets

- Quality Editorial service

- Swift Peer Review

- Reprints availability

- E-prints Service

- Manuscript Podcast for convenient understanding

- Global attainment for your research

- Manuscript accessibility in different formats ( Pdf, E-pub, Full Text, Audio)

- Unceasing customer service

Track the below URL for one-step submission https://juniperpublishers.com/online-submission.php 